\title{
Exploring professional knowledge-building through an inter-school visits programme
}

\author{
Amanda Roberts \\ University of Hertfordshire
}

\begin{abstract}
This paper explores the learning arising from a pilot inter-school visits programme in Stevenage, Hertfordshire. Teachers from two schools undertook a series of visits with the aim of developing learning and teaching in their schools. The pilot sought to understand ways in which such a collaborative visits programme could be used to build professional knowledge across school boundaries. It suggests that such knowledgebuilding is the precursor to a change of practice. An investigation of the literature reveals potential issues in making tacit knowledge visible and in recording teachers' learning so that it can contribute to a developing professional knowledge base. The paper discusses how these issues manifested themselves in practice and offers a framework for professional learning visits which underlines the continuous nature of professional learning, the need for reflection to decode what has been learned and the need for active and continuing participation by host and visitor in order to effect a change in practice. It concludes by considering the challenges of a full visits' programme and how such a programme may be used to strengthen teachers' capacity for innovation.
\end{abstract}

Keywords: professional knowledge-building, inter-school visits, innovation 


\section{Introduction}

There appears to be a deep seated belief abroad that teachers can provide the solution to all societies' ills. Each new social challenge brings the demand that schools need to address the issue and that teachers need to lead the way. Teachers' cries that they are illequipped for such challenges often meet with an equally strident demand that they undertake more 'training'. Yet 'training' is a problematic concept. The introduction of five statutory in-service training (INSET) days for all teachers in 1988 acknowledged the need for continuing professional development for teachers. However, the 'training' provided often reflected the prevalent belief in the efficacy of front-delivery, skillsbased models of practice. Differentiated development according to teacher need was rare, with the developmental potential of teacher-to-teacher dialogue seldom acknowledged. The arrival of the 'best practice' era in the late 1990s, with teachers sharing the best of what they knew with one another, appeared to be an effective reaction against this external expert, didactic model. Yet it too can be problematic with practices often being described simplistically and out of context (Hargreaves, 2003).

Teachers' professional development is a complex endeavour it appears. If education has a role to play in the development of society, how are teachers to continue to build their skills, knowledge and understanding in a way which ensures that they can meet the challenges which they face in an ever-changing world?

As a consultant working with on behalf of the local education authority and the University of Cambridge to support school improvement in Hertfordshire schools I was interested in exploring an alternative approach to professional development. A project undertaken by schools in Stevenage in Hertfordshire offered me this opportunity. 6 secondary schools and two special schools came together to explore leadership and learning in their school context. ${ }^{1}$

\footnotetext{
${ }^{1}$ This Stevenage initiative was an extension of an international project, The Carpe Vitam Leadership for Learning project, directed by a team at the University of Cambridge. This international project involved 8 universities and 24 schools in Copenhagen, Trenton (New Jersey), Brisbane, London, Innsbruck, Seattle, Oslo and Athens in collaborative action research (Frost et al; 2008). Barnwell School in Stevenage was also involved as an Associate School.
} 
In the Stevenage project, led by David Frost, schools made use of a revised Leadership for Learning baseline survey, developed during the international Carpe Vitam project. The survey instrument asks staff and students to respond to a series of statements relating to leadership and learning within their school. Teachers were also supported in exploring innovative practice through case studies/illuminative vignettes. The data served as an effective prompt for much discussion, including debate around the function of staff development in the school improvement process. Colleagues debated how they might explore and further develop collaborative practice across Stevenage. An interschool visits programme was suggested as a vehicle for sharing what teachers know. Myself and Matt Roberts, an Assistant Headteacher at Barnwell School, took the lead on developing this programme. We were interested in investigating how an inter-school visits programme can:

- support the growth of professional knowledge, with a view to using such enhanced knowledge to underpin improved practice in the participating schools at teacher, learner and institutional level

- build collaborative practice across school boundaries

\section{An approach to learning from the inter-school visits programme}

Given our agenda of improving practice rather than simply seeking enhanced understanding (Kemmis, 1993), we looked to the action research tradition to help us to conceptualise a process in which systematic inquiry would underpin both a pilot visits programme and our own subsequent reflection on this programme. The action research process was thus multi-layered, with evidence from teachers' reflections on their own personal inquiry being used by us to prompt our own understanding of the wider

process. Permission was sought from two secondary schools - Barnwell and Barclay Schools - and from individual participating teachers to use their experience to support a reflective inquiry. Both schools were happy to be named, as were the Senior Leaders involved in the project. The teachers who participated in the visits programme have been anonymised however to allow them full freedom in their reflective process. 
We wanted to help teachers to produce knowledge which was of immediate benefit to schools and which could travel (Frost, 2008). We wanted to use a strategic collection and evaluation of evidence to help us to understand the degree to which teachers felt the visits programme had allowed and supported this knowledge-building and knowledgetravel and how this might subsequently impact on their practice.

The senior leaders involved in planning within each school and participating teachers agreed to me interviewing them to learn their views on the pilot programme. I used a semi-structured interview format to promote a two-person, prompted conversation. I hoped that the interviews would not only reveal participants' views and attitudes but that they would also become an opportunity to explore knowledge and create meaning through dialogue, mirroring the purpose of the visits themselves. I used my original areas of interest in collaborative professional knowledge-building to underpin my planned questions (Cohen and Manion, 1994). Matt and I independently analysed the interview transcripts, taking an inductive approach, exploring the data in order to discover meaning rather than to verify any existing theory or hypothesis (Hitchcock and Hughes, 1995). We identified themes independently and then shared our interpretations, using the differences between us to challenge our understanding of the teachers' views and to highlight any bias or assumptions which might mask a rigorous analysis.

\section{Cross-town collaboration}

We wanted to use the visits programme to facilitate teacher reflection, stimulated by the sharing of practices made visible. We also wanted teachers to be in a position to try out the practices they had learned about, adapting and reflecting on them, moving from best practice to next practice (Hannon, 2007) across school boundaries. The development of collaborative, open working partnerships across schools brings its own challenges, however. Vestiges of the competition between schools, heralded by the introduction of grant maintained status in 1988 and later changes to admission rules, often remain. Fortunately, Stevenage project teachers were united by a shared moral purpose which strengthened their potential for collaborative success (Hargreaves and Fullan, 1998). They saw improving learning and teaching, and thus better providing for the needs of 
students in both schools, as of paramount importance, above those of inter-school competition.

In years gone by we were all competing against one another and you would never have spoken to the enemy. And the good ideas we had you wouldn't share. It's daft being anything other than co-operative.

Teacher 1, School A

I didn't feel any sense of competition. I wasn't going there to compete ... that wasn't my mindset at all. It was a genuine curiosity about how they operated this particular system.

Teacher 2, School A

We wanted the visits programme to have an impact on learning at teacher, student and institutional level. Stevenage schools are in a strong position to allow this ambitious aim to be realised, due to their robust collaborative intent and practice. Stevenage Headteachers have long viewed collaboration as a key lever in raising standards. The new National Curriculum gives hope that the dominant discourse is moving away from accountability to innovation (QCA, 2007), providing further potential for collaborative working. The Children's Plan (DCSF, 2007) places collaboration at institutional level at the centre of its drive to make teaching a Masters' level profession, whilst the Teachers' Development Agency Professional Standards for Teachers framework (TDA, 2007) cites reflective, collaborative practice as one of the necessary professional skills of all qualified teachers. Whilst it should be acknowledged that current uncertainties in the political landscape may yet challenge this collaborative intent, national and local support for collaborative professional learning provided a positive backdrop for the cross-schools visit programme.

\section{Devising the inter-school visits programme}

The National College for School Leadership's (NCSL) work on networked learning was influential as we devised the programme. We were attracted by NCSL's description of the four distinct learning processes of networked learning: learning from one another, learning with one another, learning on behalf of one another and meta-learning. The first two processes - learning from and with one another - particularly resonated with 
the experience we were striving to provide for teachers, that is, to help them to use and adapt what others know in order to realise and release their own, enhanced knowledge (Hargreaves, 1998). The distinction between networking and networked learning in the NCSL literature was similarly helpful to our thinking. We wished the visits programme to be the latter, 'purposeful, designed, sustained and facilitated' (NCSL, 2006a:4), with Matt and myself taking on the facilitation role.

There are six steps in the Networked Learning Study Visits programme (NCSL, 2006b).

Step 1 - Agreeing a focus

Step 2 - Establishing a team

Step 3 - Planning and preparation

Step 4 - Undertaking the inter-school visits

Step 5 - Following up

Step 6 - Looking forward

These steps provided us with an initial structure for facilitating the programme's development. We considered how we could direct and support teachers at each step to ensure the maximum potential for teacher learning. The spiral cycles of action research - planning, acting, observing and reflecting (Kemmis, 1993) seemed to resonate here. The 'three fields of knowledge' model of learning, presented by the NCSL to describe networked learning, offered us another way of conceptualising our hopes for the programme. Here, learning is seen as a product of a dynamic relationship between what is known from research, what we know as practitioners, and new knowledge which practitioners create together through collaborative research (NCSL, 2006c). We were particularly keen to acknowledge the second of these, teachers' knowledge, and to assert its' validity alongside that created through research and reform (Lieberman and Gronick, 1996 cited in Lieberman, 2005).

We equally appreciated that, in the very act of making their knowledge visible, host teachers were investigating it themselves anew. We wanted to avoid the visits programme encouraging 'educational tourism' but instead wished to use it to bring 
together individuals from different environments 'to engage in purposeful and sustained developmental activity...co-constructing new knowledge together' (NCSL, 2006a:3) in conditions which encouraged peer to peer learning (Hargreaves, 2003). In contrast to the 'Inside Knowledge' scheme (DCSF, 2010), we wanted to emphasise that both host and visitor are in possession of knowledge worth sharing. We therefore developed a framework which constructed the visits as small-scale enquiries - Figure 1. We shared this framework with the teachers at a pre-visit meeting and asked that they use this to guide their thinking and actions.

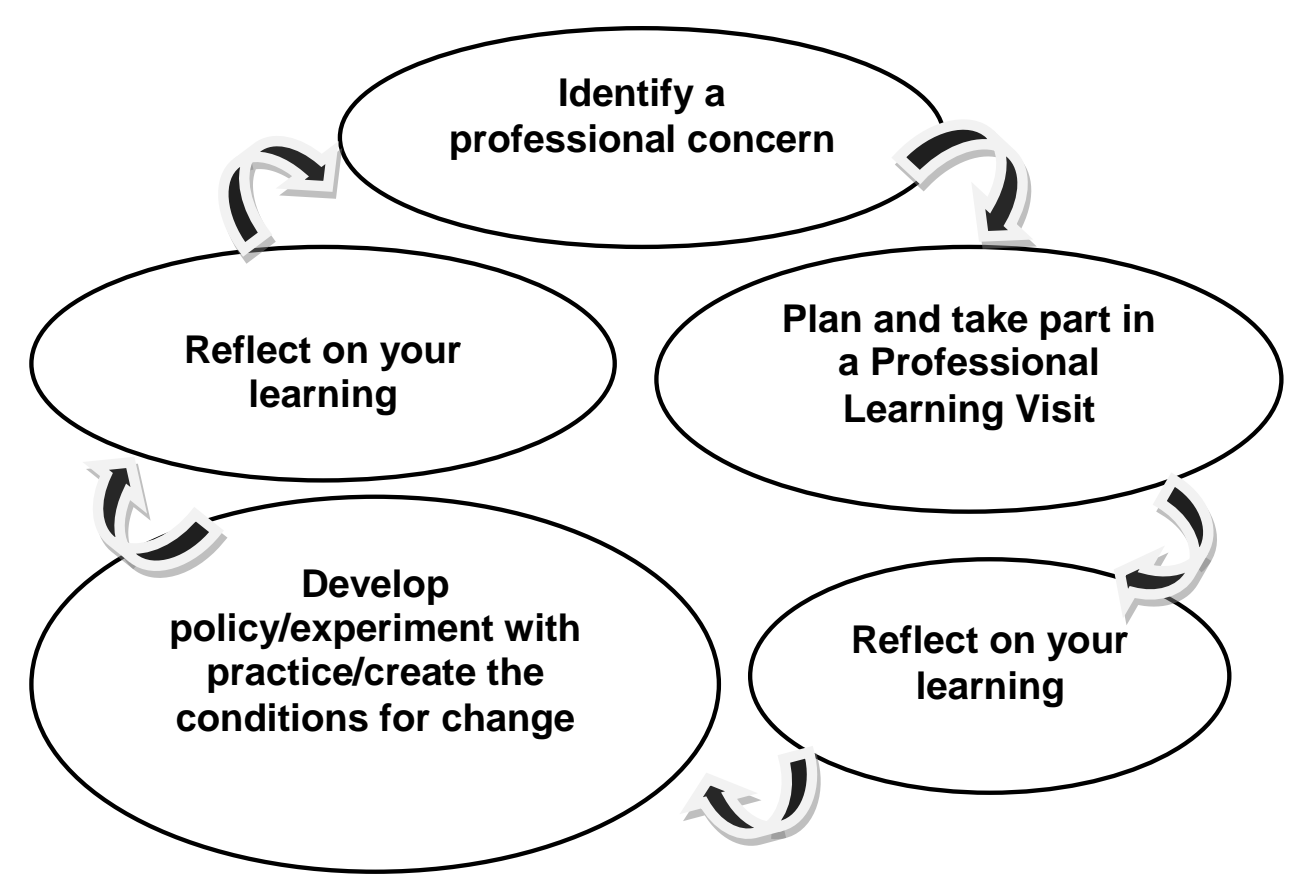

Figure 1: Professional Learning Visits - Model 1

This framework was intended to underline the continuous nature of professional learning, the need for reflection to 'de-code' what had been seen/learned and the need for such new knowledge to underpin action in order to transform something. Our hesitancy in referring directly to transforming knowledge due to the short time scale and limited scope of the visits' programme was a flaw in the model. I believe teachers would have been more prepared to share what they had learned and take strategic action 
if we had been explicit about the importance of this stage for supporting inter-school learning. It was clear that this level of impact was the vision of the senior leaders in the visit schools.

I think it becomes my responsibility to work with them (the visiting teachers) to integrate what they've learned into the school system, whatever that might be.

Senior Leader, School B

The teachers themselves saw the lack of sharing as a weakness of the programme, an issue which I return to below.

Coming back and actually sharing. At the moment it's a bit compartmentalised between us that went. How do we get that down to tutors?

Teacher 3, School B

\section{Making knowledge visible - revealing teachers' 'taken for granted' practice}

We needed to support teachers in making visible what they are doing, removing the invisibility of thinking, making explicit both the practice and the thinking behind the practice (Perkins, 2003). Polanyi's (1966) discussion of tacit versus explicit knowledge was helpful. He describes tacit knowledge as highly personal, deeply rooted in an individual's actions and experiences, their 'know-how' and in their embraced values. It is not easy to express. Much of teachers' knowledge is recognisable in this description. Explicit knowledge, conversely, can be more easily transmitted. It can be expressed in words or numbers and captured in records. With this distinction in mind, we crafted practical tools to allow teachers to share what they implicitly know and allow for the development of practice.

We believed that encouraging teachers to learn from reflection would support the transfer of knowledge (Fielding et al; 2005). We therefore offered teachers a thinking routine developed by David Perkins and his team at Harvard University to help them to consider the practice they were seeing and hearing about. The routine can be summarised as:

Connect: How are the ideas and information connected to what you know already? 
Extend: What new ideas did you get that extend your thinking in new directions?

Challenge: What is still challenging or confusing for you? What questions or puzzles have been raised?

(Perkins, 2003)

The thinking routine helped to challenge the belief that good practice from one school can be transferred to another without teacher engagement. Instead, it encouraged teachers to connect actively with what they were seeing, to engage in the purposeful and sustained development activity discussed above, with the potential to use what they were learning to enhance knowledge and practice.

\section{Planning for impact}

Given that the tacit nature of teacher knowledge makes it difficult to mine and hence difficult to share (Polanyi, 1966; Desforges, 2005; Fielding et al., 2005), we wondered if planning the learning conversations would help to ensure that teachers' dialogue deepened beyond the superficial (NCSL, 2005). We decided to use a schedule of questions devised by David Frost to help teachers to engage in planned learning conversations which would have the potential to impact on school policy and practice and on student learning. A full cross-town visits programme will only be sustainable if it impacts at these various levels, a point recognised by the senior leaders in the visit schools.

I believe that looking to impact at all levels within the education system will lead to sustainable change rather than short term, initiative-driven change.

Senior Leader, School A

We therefore adapted Frost and Durrant's (2003) impact tool to help teachers to plan for their desired impact prior to the visit and to evaluate actual impact post-visit. 


\section{The unfolding project - teachers' voices}

The six steps in the Networked Learning Study Visit's programme (NCSL, 2006b), which influenced us at the planning stages, are used below as a device to structure a discussion of the unfolding project, as revealed through participant teachers' voices.

\section{Steps 1 and 2 - Agreeing the focus and establishing a team}

Teachers from Barclay School and Barnwell School formed the first visit team. Three teachers from each school with a pastoral-based role were asked if they wished to take part in the visits, with supply cover provided where needed. We wanted to support teachers in using their Professional Learning Visit to explore an area of practice which they were interested in making a difference to. In practice however, due primarily to time constraints, the focus of the pilot visits was decided by the project co-ordinators at the two schools. A common focus across both schools was also seen to provide more fertile ground for discussion and teacher learning. This focus was identified as aspects of both schools' pastoral systems: vertical tutoring, the house system and student mentoring, with each visitor focusing on one specific area.

The teachers themselves saw the logic of being approached to take part in a Professional Learning Visit and of the chosen theme.

Matt had already looked at the picture from the two schools and identified where the biggest hole was. And that probably is our biggest hole, mentoring, academically, the students in the House System.

Teacher 1, School A

Richard Wallace asked me in my role as Learning Mentor if I would mind going across to Barnwell School and finding out from them how they carry out mentoring.

Teacher 1, School B

The institutional nature of the theme did not seem to limit the teachers' enthusiasm or learning. On the contrary, they appeared to be pleased to be asked to share knowledge 
which was both related to their particular role within school and, by implication, could also impact at a whole-school level.

A partnership between professionals so that they can learn from each other and share good practice.

Teacher 2, School A

Share knowledge; see what someone doing my job at another school does; share good practice.

Teacher 3, School B

\section{Step 3 - Planning and preparation}

We produced two booklets to support teachers in making their own practice visible and in engaging with others' practice in a way which allowed them to reflect and innovate. A Pre-Visit Briefing was introduced to teachers at a pre-visit meeting to allow teachers time to read through the supporting information and plan their approach to the visit. A Visit Support Booklet was designed to support teachers in reflecting and recording thoughts on the visit itself, helping them to both capture what they saw and to make meaning from it. This booklet included the connect-extend-challenge thinking routine and the schedule of interview questions.

Teachers' reactions to these booklets were mixed. Some found them central to their developing understanding; for most, however, they appeared almost a hindrance.

I did use the books but I found the way in which they were written and the language they used did not suit what I was doing.

Teacher 3, School A

For some teachers, their importance was a symbolic one, signaling the visits as valuable opportunities for legitimate professional networking and development.

It gave it some gravitas, it sets the platform for the professional dialogue

Teacher 2, School A 
With more structure it's not just me going out for a day and having a chat and a nice bit of lunch.

Teacher 3, School A

\section{Steps 4 and 5 - Undertaking the inter-school visits and following up}

Teachers spent approximately two hours at the host school, having been paired with another teacher with a similar area of expertise and interest. Each pair structured their time as suited them. The teachers' experience of the visits is explored through the themes below.

\section{Professional relationships}

Many teachers saw their relationship with their partner visit teacher as key to the visits' success as a learning process. Feelings before the visits ran high.

I didn't know what I would say to these people. Who am I to say how to do anything and I was really worried about how to prepare.

Teacher 1, School B

Teachers' experience of the visits themselves proved to be far more emotionally positive than some had perhaps anticipated. This in turn supported their learning.

It was very much 'we want to share'. You didn't feel you were putting on them. It was all very open and free-flowing.

Teacher 2, School B

The guy I spoke with, I get on with quite well. We were in a position where we can say to each other quite candid things.

Teacher 3, School A

Positive relationships thus offered the potential for critical analysis of practice as well as affirmation. The importance of relationships was similarly recognised by the senior leaders. 
I think that visit coordinators within individual schools need to establish common ground and develop a good working relationship before the actual visits take place.

Senior Leader, School A

It's also to some extent about developing personal relationships ... I'm not sure what it would be like if a school we didn't have close links with rang and said they would like to do some Professional Visits. I don't know, it might work, it would depend on what it was but there is a greater openness if you have developed a cultural association with another school.

Senior Leader, School B

Many of the building blocks of social capital - trust, engagement and connection, shared values and aspirations (West-Burnham and Otero, 2005) - are highlighted here. An unexpected outcome of the visits was the affirmation which teachers gained from a fellow professional's positive response to their practice.

My main thing this visit was that I don't think we are doing such a bad job.

Teacher 3, School A

The ability of colleagues from another school to support positive teacher self-evaluation was both recognised and greatly valued, leading to a rekindling of professional pride (Hargreaves, 2003).

I felt that I had given them something worthwhile and it made me realise that actually what I do is quite a good job and sometimes you don't get that from your own school. Sometimes you have to have someone from the outside looking in to help you to realise that what you do is difficult and you do it well and it's not just the expected norm. There is a lot of reinforcement in someone saying 'oh, I really like the way you are doing that as well'.

Teacher 1, School B

The confidence which this feel-good factor gave visit participants appeared to allow them the freedom to question their own practice, rather than adopt a defensive attitude. Real professional reflection and growth could then occur, supported by the tools provided in the teachers' support booklets. 
It was helpful to have that information to see the different sorts of impact and that made me reflect on that and also to have the grid where you had to talk about what you saw and how it linked to what you currently did and what your expectation was and what was challenging. I thought that was very helpful.

Teacher 2, School A

\section{The power of teacher talk}

All of the teachers who took part in a Professional Learning Visit commented on the power of teacher dialogue in promoting learning.

We were able to have a natural conversation ... I think that's the best sort of conversation ... you think of questions so it is quite productive.

Teacher 2, School A

Reflecting on Ball's (1987) comments on the power structures within talk, we were interested to discover who controlled the agenda; did teachers feel they were engaging in a reciprocal dialogue, and therefore relationship, on both their home school and host school sites? For some teachers, the location of the learning conversation was irrelevant to either the leadership of the dialogue or the possibilities for learning arising from it.

The site that we were at didn't really make a difference to the conversation. Neither of us was leading.

Teacher 1, School B

For others, the role of learner was more closely associated with the role of visitor rather than host.

Probably more going there because that was finding out about what they did whereas I felt them coming here was about them finding out what we did, which was more about reinforcing our systems.

Teacher 1, School A

For some teachers then, learning was defined as layering new ideas and concepts onto existing knowledge. For others, professional dialogue prompted reflection on their own 
practice, on what they thought they already understood, to create new understanding (West-Burnham and Otero, 2005). Making practice visible through talk and reflection, making the familiar strange, was very powerful for these teachers.

When someone comes and they are new and they are looking at something very objectively they do ask you questions that make you reflect. It's about perception isn't it. You don't always see things in the way in which a stranger might see them. You are so used to working through processes that are familiar to you that you don't question them.

Teacher 2, School A

When you are doing your own job you don't see sometimes ways of doing it differently or moving forward because you are almost fire fighting on a daily basis. Once you take yourself out of that and you see how it can be done or that might not be right, it gives you that looking in perspective doesn't it rather than being involved.

Teacher 2, School B

Our concerns around the difficulty of making practice visible through such dialogue appeared to be unfounded, although for some, a longer visit would have yielded additional benefits.

I didn't find it difficult but then I think the ground had been laid that it was going to be a fact finding exercise. I didn't find it difficult to initiate things - how do you do this and how do you do that. Or to think of a scenario.

Teacher 2, School A

It's all very well telling you, well we do this, this and this, but each individual is different and dealt with in a different way. You almost want to be invisible and sit on their shoulder for a day.

Teacher 2, School B

\section{The link between knowledge and know-how: influencing policy and practice}

The teachers who took part in the visits programme were keen to share what they had learned with others on return to their own school and to use their increased knowledge to impact on policy and practice. All of the teachers believed their school culture to be allowing of this level of teacher voice and suggestion. 
That's a dialogue which needs to happen (talking to the Leadership Team) and I would be very keen for that to happen.

It's much more about different people doing; it doesn't all come from the Leadership Team at all ... they are not from formal leadership roles, they're more from people who have ideas and want to share them.

Teacher 1, School B

Despite this acknowledged structural potential for sharing and indeed for leadership, the teachers did not share what they had learned widely within their schools. Informal discussion took place amongst those who had taken part in the visits but the formal, strategic discussions necessary for transformation did not take place.

We have talked about some of the things that we brought back but we haven't had any formal conversations... we could have had a whole meeting where the three of us fed back to the other people who do our role in the school. Maybe we could have done something like that as a follow up.

Teacher 1, School B

The teachers generally saw the reasons for this omission as being operational rather than strategic or political. However for some, a difficulty arises in re-creating an experience for others.

The idea was to bring back information for the four house leaders which we have shared amongst the four of us. But it is difficult, when you are there and you are feeding off it and you come back and say, 'well I've got this sheet' ... what does that mean?

Teacher 2, School B

We clearly needed to provide further support for knowledge transfer if we wished such knowledge to impact on practice.

\section{Supporting knowledge transfer}

We wanted to ensure that teachers not only noticed and reflected on their own and others' practice, but also that they recorded what they had learned in a formal way. We 
saw this as a key step towards deepening their own understanding of what they had 'noticed', rendering it not only an object of analysis but also a component in the making of meaning (Mason, 2002). We hoped that this would help to support participant teacher learning and the learning of other teachers in the participants' schools. We provided teachers with a writing frame, together with a completed example. However, none of the teachers involved undertook any formal recording of their learning, nor did they complete the evaluation of impact of their visit. Given that such recording is crucial to knowledge-building, we needed to explore the reasons for this.

The teachers recognised the need for some sort of recording but were generally thinking in more pragmatic terms about its nature.

The bit about what I thought I was going to get out of it was important. And the opportunity to record the observation needs to go somewhere.

Teacher 1, School A

We therefore produced a revised evaluation of impact sheet and reissued it to teachers to complete. We hoped that combining a request to log what teachers had learned with an evaluation of impact would more helpfully support the learning process. Although teachers did complete this, the information they provided was sketchy and still did not seem an appropriate vehicle for knowledge-sharing. We clearly needed to develop a new approach to supporting knowledge-building in the full visits programme.

\section{Step 6 - Looking forward}

The pilot had provided us with an interesting insight into how to develop a full interschools visits' programme which supports professional knowledge-building. We reflected on our learning in order to plan the way forward.

\section{Key outcomes - reflecting on the learning}

We wished to use the pilot visits' programme to provide a powerful, active learning experience for Stevenage teachers. We therefore needed to structure the programme so 
that it provided support for teachers to learn from one another and to use that learning to make a difference (Fullan, 1999). In reality, both aims proved challenging to achieve.

The inter-school visits were difficult to organise. Finding appropriate times during the school day for teachers to visit their partner school was problematic. This difficulty is likely to increase in the context of restrictions now placed on schools by the rarely cover' guidelines (TDA, 2003). It was similarly challenging for the teachers to find time to reflect together on what they had learned, to record this in an appropriate medium for a wider audience and to find the forum in their home school for sharing their insights. In struggling to overcome these difficulties we returned to the knowledge management literature.

We recognised Tabberer's (2003) description of knowledge management as a process which makes available people's knowledge about what works, so that colleagues can use it. Arian Ward's view, quoted in Collison and Parcell (2004), was more challenging however.

It's not about creating an encyclopedia that captures everything that anybody ever knew. Rather, it's about keeping track of those who know the recipe, and nurturing the culture and the technology that will get them talking.

(Collison and Parcell, 2004:16)

We realised that we had worked on ways of capturing knowledge, providing teachers with proformas and templates, yet had not attempted to influence the underlying culture in which we expected these tools to be effective. We thus viewed knowledge as static and knowable, rather than organic and requiring appropriate conditions in which to flourish. Nonaka and Takeuchi (1995) suggest that organisations wishing to move knowledge from tacit to explicit states should concentrate on improving four central processes: socialization, externalistion, combination and internalization (SECI). Socialisation involves helping people to learn from others through face to face experience, externalisation is the process of talking or writing about what you know, with combination then used to make knowledge more systematic. Internalisation occurs when what you know is built into what you do. We wondered about ways in which this business model could be applied to schools. Snowden (2002) addresses the 
complexity and flow of knowledge by suggesting that systems vary in terms of their knowledge base. This can be complicated but 'learnable' or complex and hard to penetrate. This was helpful to our thinking. Teachers' tacit knowledge would be an example of complex knowledge. An understanding of the differences in the various types of knowledge which arise from the visits programme therefore appears crucial in supporting the growth of that knowledge.

Based on this strengthened understanding of knowledge management, we produced a revised Professional Visits model, Figure 2 below.

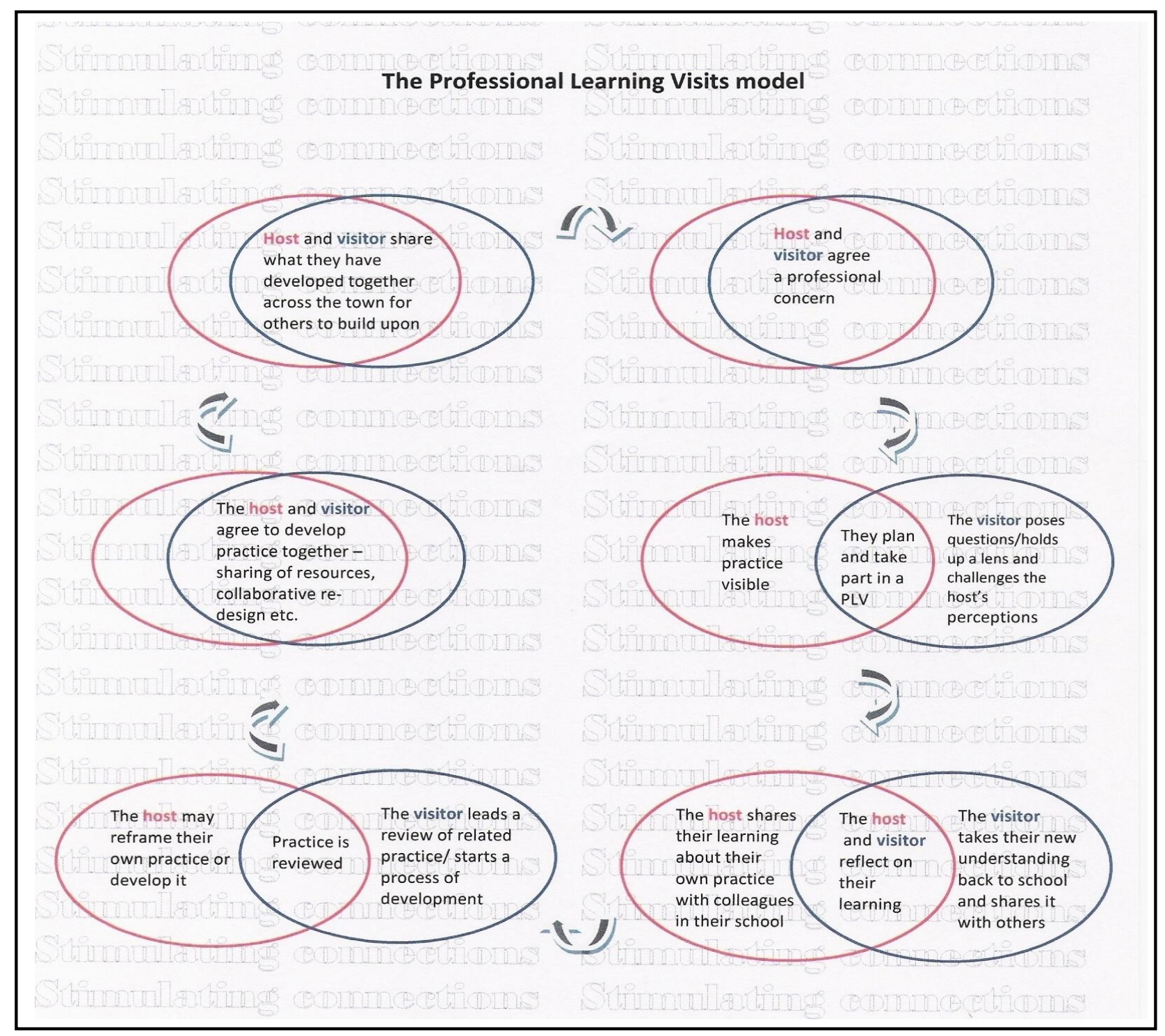

Figure 2: Professional Learning Visits - Model 2 
This model emphasizes the need both to do something differently as a result of professional learning and to represent new knowledge so that it can be shared with others. The significance of the unseen connections between individuals is underlined through the repetition of the words stimulating connections (Collison and Parcell, 2004) as a background shadow to the model. This model now signified the importance of a culture of connectivity, of sustaining interconnected communities of practice (Wenger, 1998) to provide appropriate conditions for effective steps towards knowledge management and learning at individual, school and system levels. It also makes explicit the active participation needed from both host and visitor, both during and post-visit.

\section{The way forward}

We wanted to support teachers in making their knowledge visible so that others could learn from them. On reflection, we perhaps offered a confusing variety of tools to visit participants in our attempt to help them to achieve this. We have since streamlined the supporting material for teachers, making the connect-extend-challenge routine central to all tools used to prompt both reflection and recording. Dialogue, and hence learning, is impeded if time is not provided to allow teachers to meet. We need to re-think the time-frame of the visits to ensure that teachers have time to reflect together on their return to school, before preparing to share their developing knowledge more widely.

Teachers took a clear leadership role in sharing their knowledge with their visit partner. We neglected to pay adequate attention to supporting teachers in using, building on and sharing their new knowledge more widely, however. John Dewey's exhortation that the map is not the journey (Dewey, cited in Mason, 2002) helped our thinking on this point. We can give teachers tools to guide them on their way to building professional knowledge but the journey has to be their own, personal and unique, rather than common and imposed. It is only by challenging Stevenage schools to invent suitable knowledge management systems for themselves that sustainable progress will be possible. In this age of austerity and with diminishing Local Authority support it is perhaps even more important to retain such localized approaches. 
It is becoming clear that a stand-alone, cross-school visits programme is not part of this sustainable future. We need instead to mine the potential of inter-school visits to enrich and extend the learning of existing groups of teachers, for example, Learning and Teaching groups, currently working in isolation in individual schools. In this model, teachers have a ready-made forum for feedback to colleagues in their home school, with the potential for wider impact. Schools' capacity to experiment with new ideas, and to build new knowledge, should thus be increased (Fullan, 1999). We also hope that this focus on individual interest and timeframe, leading to personal strategic action, will enhance teachers' sense of their own agency (Frost, 2006), of their ability to lead innovation within their school and across the town.

A note of caution does need to be struck here however. Any move to individualise learning opportunities could re-focus the Professional Learning Visits programme as purely continuing professional development for the individual. Whilst this is undoubtedly an important aspect, it is only the first step in the learning and knowledgebuilding we were seeking to support. We cannot simply assume that continuing professional development will automatically lead to system learning (Frost, MacBeath, Swaffield and Waterhouse, 2008). We need instead to develop further ways to support the transfer of internal knowledge into the public domain.

Formalising the use of the revised Professional Visits' model may help to develop teachers' capacity for transformational leadership through enquiry-based development (Durrant and Holden, 2006). The 'stimulating connections' aspect of the model will need further consideration however, so that town-wide knowledge can begin to be built. We remain a long way from understanding what Stevenage as a town knows. This focus on sustainability needs to take account of the cost of transferring knowledge. Von Hipple (1994) points out the cost of transferring what he calls' sticky information', that is, information which is difficult to move because of its tacit nature. Schools need to invest in supporting the movement and growth of such knowledge. The vision for collaboration across Stevenage, given by the Headteachers on the Stevenage Partnership website (Stevenage Partnership, 2010) talks of working together to transform the educational culture of the town. The inter-school visits programme could perhaps 
provide a vehicle for debate and reflection which would support such cultural transformation. The transformation of practice requires that we engage in such dialogue in order to face the challenges of moving from a pilot study to a whole-town approach. 


\section{References}

Ball, S. (1987) The micro-politics of the school. London: Methuen.

Cohen, L. and Manion, L. (1994) Research methods in education. London: Routledge.

Collison, C. and Parcell. G. (2004) Learning to fly. Sussex: Capstone.

DCSF (2007) The Children's Plan. Available online:

http://www.dcsf.gov.uk/childrensplan/ Accessed: 24 April 2010.

DCSF (2010) New visits programme launched to help schools learn from the best.

Available online: http://www.dcsf.gov.uk/pns/DisplayPN.cgi?pn_id=2010_0083

Accessed: 4 May 2010.

Desforges, C. (2005) On learning and teaching. Nottingham: NCSL.

Durrant, J. and Holden, G. (2006) Teachers leading change. London: Paul Chapman Publishing.

Fielding, M. Bragg. S., Cunningham, I, Erault, M., Horne, M., Robinson, C. Thorpe, J. (2005) Factors affecting the transfer of good practice. Research report RR615. London: DfES.

Frost, D. and Durrant, J. (2003) Teacher Led Development Work. London: David Fulton.

Frost, D. (2006) The concept of 'agency' in Leadership for Learning. Leading and Managing. 12 (2) 2006 pp.19- 28.

Frost, D. (2008) 'Researching the connections, developing a methodology' in MacBeath, J. and Dempster, N. Connecting Leadership and Learning Principles for Practice. London: Routledge.

Frost, D. with Bolat, O., Frost, R. \& and Roberts, A. (2008) The legacy of the Carpe Vitam LfL project: helping schools to collaborate in a climate of competition, a paper presented within the symposium 'The Carpe Vitam LfL project' at ICSEI 2008: The $21^{\text {st }}$ annual meeting of the International Congress for School Effectiveness and Improvement Auckland, New Zealand, January 2008.

Frost, D., MacBeath, J., Swaffield, S. and Waterhouse, J. (2008) 'The legacy of the Carpe Vitam Leadership for Learning project', Inform No. 8, Occasional papers published by 'Leadership for Learning: the Cambridge Network February 2008.

Fullan, M. (1999) Change Forces: the sequel. London: Falmer Press.

Hannon, V. (2007) 'Next practice' in education: a disciplined approach to innovation. DCSF: The Innovation Unit. Available online: 
http://www.innovation-unit.co.uk/about-us/publications/next-practice-in-education.html Accessed: 23 June 2008.

Hargreaves, A. and Fullan, M. (1998) What's worth fighting for in Education? Buckingham: Open University Press.

Hargreaves, D. (1998) Creative professionalism: The role of teachers in the knowledge society. Demos Arguments series 22.

Hargreaves, D. (2003) Working laterally: how innovation networks make an education epidemic. Nottingham: DfES.

Hitchcock, G. and Hughes, D. (1995) Research and the teacher: A qualitative introduction to school-based research ( $2^{\text {nd }}$ edition). London: Routledge.

Kemmis, S. (1993) 'Action Research’ in M. Hammersley (Ed) Educational

research: current issues. London: Paul Chapman Publishing.

Lieberman, A. (2005) Networks. Nottingham: NCSL.

Mason, J. (2002) Researching your own practice. The discipline of noticing. London: RoutledgeFalmer.

Nonaka, I. and Takeuchi, H. (1995) The SECI model. Available online:

http://www.12manage.com/methods_nonaka_seci.html Accessed: 18 June 2008.

NCSL (2005) Learning conversations in learning networks. Nottingham: NCSL.

NCSL (2006a) What are we learning about ... ? sustaining a network of schools. Nottingham: NCSL.

NCSL (2006b) Network leadership in action: Getting started with Networked Learning study-visits. Nottingham: NCSL.

NCSL (2006c) Learning about learning networks. Nottingham: NCSL.

Perkins, D. (2003) Making thinking visible. Available online:

http://www.newhorizons.org/strategies/thinking/perkins.htm Accessed 2 January 2008.

Polanyi, M. (1966), The Tacit Dimension. London: Routledge and Kegan Paul.

QCA (2007) The National Curriculum website. http://curriculum.qca.org.uk/ Accessed 7 May 2008.

Snowden, D (2002) 'Complex acts of knowing: paradox and descriptive selfawareness'. Journal of knowledge management. 6 (2) pp.100-111. 
Stevenage Partnership. Available online: http://www.stevenage1419.org.uk/ Accessed: 28 April 2010.

Tabberer, R. (2003) Knowledge and Innovation - 'five easy pieces'. London: TTA.

Training and Development Agency (2003) Raising standards and tackling workload: a national agreement. Available online: http://www.tda.gov.uk Accessed: 21 October 2010

Training and Development Agency (2007) Professional Standards for Teachers Framework. London: TDA.

Von Hipple, E. (1994) "Sticky information" and the locus of problem-solving: implications for innovation'. Management Science, 40. No. 4 April 1994 pp.429 - 439.

Wenger, E. (1998) Communities of practice: learning, meaning and identity. New York: Cambridge University Press.

West-Burnham, J \& Otero, G. (2005) Leading together to build social capital, What are we learning about...? Community leadership in networks. Nottingham: NCSL. 